\title{
Analisis Simetri Lie Persamaan Diferensial Painleve Ince
}

\author{
Maulana Malik ${ }^{1}$, Siti Sabariah Abas ${ }^{2}$, Mustafa Mamat ${ }^{3}$ Dan Sukono ${ }^{4}$ \\ ${ }^{1}$ Departemen Matematika, Universitas Indonesia, Indonesia, m.malik@sci.ui.ac.id \\ ${ }^{2,3}$ Faculty of Informatics and Computing, Universiti Sultan Zainal Abidin, Terengganu, \\ Malaysia, sabariahabas@unisza.edu.my, must@unisza.edu.my \\ ${ }^{4}$ Departemen Matematika, Universitas Padjadjaran, Bandung, Indonesia, \\ sukono@unpad.ac.id
}

\begin{abstract}
Abstrak
Penentuan koordinat kanonik merupakan hal yang diperlukan dalam penentuan solusi persamaan diferensial dengan menggunakan metode Simetri Lie. Pada tulisan ini dibahas penentuan koordinat kanonik dari persamaan diferensial Painleve Ince dan mereduksinya menjadi persamaan diferensial orde satu. Hasil pembahasan dari paper ini yaitu metode Simetri Lie dapat digunakan untuk menentukan solusi eksak persamaan diferensial Painleve Ince.

Kata Kunci: Koordinat Kanonik, Metode Simetri Lie, Persamaan Diferensial Painleve Ince, Persamaan Diferensial Orde Satu.
\end{abstract}

\begin{abstract}
Determination of canonical coordinates is necessary in determining the solution of differential equations using the Lie Symmetry method. In this paper we discuss the determination of canonical coordinates of the Painleve Ince differential equation and reduce them to first-order differential equations. The results of the discussion of this paper of Lie Symmetry methods can be used to determine the exact solution of Painleve Ince differential equations.

Keywords: Canonical Coordinates, Lie Symmetry Method, Painleve Ince Differential Equation, First Order Differential Equations .
\end{abstract}

\section{Pendahuluan}

Pada pertengahan abad ke 19, seorang ahli matematika dari Norwegia yang bernama Sophus Lie mengemukakan suatu teori yang disebut sebagai teori grup transformasi yang saat ini lebih dikenal sebagai teori grup Lie. Teori tersebut terinspirasi dari teori Galois dalam teori grup hingga untuk menyelesaikan persamaan aljabar (Martinot,[1]). Sophus Lie menggunakan teori grup Lie untuk menentukan solusi dari persamaan diferensial dan mereduksi order dari persamaan diferensial sehingga mudah untuk ditentukan solusinya (Singh,[2]).

Beberapa tulisan menyebut teori grup Lie dalam penyelesaian persamaan diferensial sebagai metode Simetri Lie dikarenakan terkait dengan konsep kesimetrian. Konsep kesimetrian dapat digunakan pada suatu ekspresi aljabar. Sebagai ilustrasi, persamaan $y=x^{4}$ atau $y=\cos x$ mempunyai sifat simetri, yaitu suatu transformasi $x \mapsto-x$ memetakan grafik $y=x^{4}$ ke $y=x^{4}$ itu sendiri dan juga transformasi $x \mapsto x+2 \pi$ memetakan $y=\cos x$ kembali ke

2000 Mathematics Subject Classification: 76M60, 34C14, 34M55

Received: 2019-03-01, accepted: 2019-04-06. 
$y=\cos x$. Secara similar, solusi untuk persamaan diferensial dapat bersifat simetri dan lebih lanjut, sifat simetri tersebut digunakan untuk menentukan solusinya (Martinot,[1]).

Dalam papernya, Estevez, et al[3] membahas beberapa persamaan diferensial dan mengaitkan persamaan diferensial tersebut dengan sistem persamaan diferensial berdasarkan Simetri Lie. Salah satu persamaan yang dibahas adalah persamaan diferensial Painleve Ince, yaitu suatu persamaan diferensial orde dua dengan bentuk khusus dimana dari persamaan diferensial tersebut dibentuk suatu sistem persamaan diferensial dan mengkaitkannya dengan Simetri Lie.

Oleh karena itu, pada tulisan ini penulis tertarik untuk membahas lebih lanjut dari persamaan diferensial Painleve Ince, yaitu membahas bentuk reduksinya dan penentuan solusi eksaknya dengan menggunakan metode simetri Lie.

\section{LANDASAN TEORI}

Pada bagian ini dibahas beberapa konsep yang berkaitan dengan Simetri Lie untuk menentukan solusi persamaan diferensial. Pertama-tama diberikan terlebih dahulu definisi grup.

Definisi 2.1. (Herstein, [4]) Suatu himpunan G yang dilengkapi operasi $*$ disebut grup perkalian bila memenuhi sifat berikut:

(1) Tertutup : $g_{i} \in G$ dan $g_{j} \in G$ maka $g_{i} * g_{j} \in G$.

(2) Asosiatif : Untuk setiap $g_{i}, g_{j}, g_{k} \in G$ maka $\left(g_{i} * g_{j}\right) * g_{k}=g_{i} *\left(g_{j} * g_{k}\right)$.

(3) Identitas : Terdapat $I \in G$ sedemikian sehingga $\left(g_{i} * I\right)=g_{i}=\left(I * g_{i}\right)$ untuk semua $g_{i} \in G$.

(4) Invers : Untuk setiap $g_{i} \in G$ terdapat $g_{i}^{-1} \in G$ sedemikian sehingga $g_{i} * g_{i}^{-1}=I=$ $g_{i}^{-1} * g_{i}$.

Definisi 2.2. (Martinot, [1]) Grup Lie satu-parameter (atau transformasi Lie point) adalah grup $G$ dengan himpunan transformasi $P_{\lambda}$ sehingga kondisi berikut ini terpenuhi.

(1) $P_{\lambda}$ bersifat bijektif.

(2) $P_{\lambda_{1}} o P_{\lambda_{2}}=P_{\lambda_{1}+\lambda_{2}}$.

(3) $P_{0}=I$.

(4) Untuk setiap $\lambda_{1}$ terdapat secara unik $\lambda_{1}=-\lambda_{2}$ sedemikian sehingga $P_{\lambda_{1}} o P_{\lambda_{2}}=P_{0}=I$.

(5) Fungsi $f$ adalah fungsi kontinu pada $D \subset \mathbb{R}^{2}$ dan analitik terhadap $\lambda$.

Sebagai ilustrasi, misalkan $A$ himpunan titik $(x, y) \in \mathbb{R}^{2}$ dan $B$ himpunan titik $(\hat{x}, \hat{y}) \in$ $\mathbb{R}^{2}, P_{\lambda}$ adalah pemetaan dari $A$ ke $B$ :

$$
P_{\lambda}: A \rightarrow B
$$

dengan $\hat{x}$ dan $\hat{y}$ merupakan fungsi dari $x, y$ dan $\lambda$, misalkan saja $\hat{x}=f(x, y, \lambda)$ dan $\hat{y}=g(x, y, \lambda)$ lebih lanjut $P_{\lambda}$ dapat dituliskan sebagai

$$
P_{\lambda}:(x, y) \mapsto(\hat{x}, \hat{y})=(f(x, y, \lambda), g(x, y, \lambda))
$$

Definisi 2.3. (Martinot, [1]) Simetri persamaan diferensial adalah transformasi invertibel yang memetakan solusi ke solusi.

Sebagai contoh, misalkan diberikan persamaan diferensial orde satu

$$
\frac{d y}{d x}=\frac{y}{x} .
$$

Solusi dari (1) adalah $y(x)=c x, c \in \mathbb{R}$. Perhatikan bahwa untuk setiap $\lambda \in \mathbb{R}$, transformasi $P_{\lambda}:(x, y) \mapsto(\hat{x}, \hat{y})=\left(x, e^{\lambda} y\right)$ adalah suatu simetri karena $P_{\lambda}$ memetakan solusi $y(x)$ ke solusi $\hat{y}(\hat{x})=c e^{\lambda} \hat{x}$. Titik $(\hat{x}, \hat{y})=\left(x, e^{\lambda} y\right)$ disebut juga sebagai titik simetri.

Dalam metode Simetri Lie diperlukan suatu kondisi yang disebut sebagai kondisi simetri (disebut juga kondisi invarian). Perhatikanlah ilustrasi berikut ini, misalkan diberikan persamaan diferensial orde satu

$$
\frac{d y}{d x}=h(x, y)
$$


yang memiliki grup Lie satu parameter $P_{\lambda}:(x, y) \mapsto(\hat{x}, \hat{y})$. Karena simetri mempertahankan solusi dari persamaan diferensial (berdasarkan Definisi 2.3) maka (2) dapat dituliskan sebagai

$$
\frac{d \hat{y}}{d \hat{x}}=h(\hat{x}, \hat{y})
$$

Persamaan (3) dapat diselesaikan dengan menggunakan turunan total, yaitu dengan mencari bentuk $D_{x} \hat{x}$ dan $D_{x} \hat{y}$. Perhatikan bahwa $(\hat{x}, \hat{y})=(f(x, y, \lambda), g(x, y, \lambda))$, maka turunan total dari $\hat{y}$ terhadap $x$

$$
D_{x} \hat{y}=\frac{d \hat{y}}{d x}=\frac{d g}{d x}=\frac{\partial g}{\partial x} \frac{d x}{d x}+\frac{\partial g}{\partial y} \frac{d y}{d x}+\frac{\partial g}{\partial \lambda} \frac{d \lambda}{d x}=\frac{\partial g}{\partial x}+\frac{\partial g}{\partial y} \frac{d y}{d x}=\hat{y}_{x}+y^{\prime} \hat{y}_{y}
$$

Lebih lanjut akan didapatkan bentuk

$$
\frac{d \hat{y}}{d \hat{x}}=\frac{D_{x} \hat{y}}{D_{x} \hat{x}}=\frac{\hat{y}_{x}+y^{\prime} \hat{y}_{y}}{\hat{x}_{x}+y^{\prime} \hat{x}_{y}}=h(\hat{x}, \hat{y}) .
$$

Dengan mensubstitusi (2) ke (4) maka diperolehlah suatu bentuk yang mengartikan kondisi simetri sebagai berikut

$$
\frac{\hat{y}_{x}+h(x, y) \hat{y}_{y}}{\hat{x}_{x}+h(x, y) \hat{x}_{y}}=h(\hat{x}, \hat{y}) .
$$

Bentuk (5) disebut juga sebagai persamaan kendala (Steinhour, [5]). Kondisi simetri diperlukan untuk menentukan koordinat kanonik karena dengan koordinat kanonik suatu persamaan diferensial dapat dibentuk menjadi variabel terpisah yang dengan mudah ditentukan solusinya.

Untuk menentukan koordinat kanonik diperlukan beberapa pengetahuan, diantaranya adalah vektor singgung pada arah $x$ (dinotasikan sebagai $\xi(x, y)$ ), vektor singgung pada arah $y$ (dinotasikan sebagai $\eta(x, y)$ ), prolongation, persamaan penentuan (menggunakan infinitesimal generator) dan bentuk Lagrange. Di bawah ini akan dibahas lebih lanjut maksud dari istilahistilah tersebut.

Vektor singgung satuan dapat diperoleh dengan cara berikut :

Perhatikan bahwa

$$
\frac{d \hat{x}}{d \lambda}=\xi(\hat{x}, \hat{y}), \frac{d \hat{y}}{d \lambda}=\eta(\hat{x}, \hat{y})
$$

dengan mengambil $\lambda=0$ maka

$$
\left(\left.\frac{d \hat{x}}{d \lambda}\right|_{\lambda=0},\left.\frac{d \hat{y}}{d \lambda}\right|_{\lambda=0}\right)=(\xi(x, y), \eta(x, y)) .
$$

Selanjutnya diberikan definisi first prolongation.

Definisi 2.4. (Gilmore,[6]) First prolongation didefinisikan sebagai

$$
\zeta\left(x, y, y^{\prime}\right)=\eta_{x}+\left(\eta_{y}-\xi_{x}\right) y^{\prime}-\xi_{y} y^{\prime 2}
$$

Untuk menentukan persamaan penentuan diperlukan bentuk Infinitesimal generator. Infinitesimal generator didefinisikan sebagai

$$
X \equiv X\left(x, y, y^{\prime}\right)=\xi(x, y) \frac{\partial}{\partial x}+\eta(x, y) \frac{\partial}{\partial y}+\zeta\left(x, y, y^{\prime}\right) \frac{\partial}{\partial y^{\prime}}
$$

(Gilmore,[6]). Terkadang bentuk (9) hanya dituliskan sebagai $X(x, y)=\xi(x, y) \frac{\partial}{\partial x}+\eta(x, y) \frac{\partial}{\partial y}$ (Steinhour, [5]). Kemudian pandang fungsi $F\left(x, y, y^{\prime}\right)$ dan tuliskan bentuk $X F=0$ yaitu

$$
\xi(x, y) \frac{\partial F}{\partial x}+\eta(x, y) \frac{\partial F}{\partial y}+\zeta\left(x, y, y^{\prime}\right) \frac{\partial F}{\partial y^{\prime}}=0
$$

Persamaan (10) disebut sebagai persamaan penentuan (the determining equation) (Gilmore,[6]). Kemudian dari (10) dapat diperoleh bentuk Lagrange sebagai berikut :

$$
\frac{d x}{\xi(x, y)}=\frac{d y}{\eta(x, y)}=\frac{d p}{\zeta\left(x, y, y^{\prime}\right)}
$$

dengan menyelesaikan bentuk Lagrange inilah koordinat kanonik akan diperoleh. 
Definisi 2.5. (Martinot, [1]) Koordinat kanonik $(r(x, y), s(x, y))$ dari persamaan diferensial adalah koordinat yang mana persamaan diferensial dalam bentuk terpisah.

Bila $(r(x, y), s(x, y))$ menyatakan koordinat kanonik dan menggunakan bentuk (5) maka diperoleh persamaan berikut :

$$
\frac{d s}{d r}=\frac{s_{x}+y^{\prime} s_{y}}{r_{x}+y^{\prime} r_{y}}
$$

dan lebih lanjut solusi persamaan diferensial akan didapatkan.

\section{Penyelesaian Persamaan Diferensial Painleve Ince}

Pada bagian ini akan dibahas cara penentuan solusi eksak dari persamaan diferensial Painleve Ince. Dalam papernya, Estevez [3] mendefinisikan persamaan diferensial Painleve Ince sebagai persamaan diferensial orde dua sebagai berikut

$$
\frac{d^{2} y}{d x^{2}}=-3 y \frac{d y}{d x}-y^{3}
$$

Langkah awal untuk menentukan solusi (13) dengan metode Simetri Lie adalah mereduksi persamaan tersebut menjadi persamaan diferensial orde satu dengan memanfaatkan bentuk vektor singgungnya. Penentuan vektor singgung untuk persamaan diferensial berorde lebih dari satu memerlukan proses yang cukup panjang. Oleh karenanya, untuk mempersingkat proses penyelesaian, vektor singgungnya dicari dengan Detools symgen pada software Maple, sehingga diperolehlah bentuk vektor singgungnya sebagai berikut :

$$
(\xi(x, y), \eta(x, y))=(1,0)
$$

Menurut Singh [2], untuk mereduksi order persamaan diferensial dapat menggunakan bentuk Lagrange sebagai berikut :

$$
\frac{d x}{\xi(x, y)}=\frac{d y}{\eta(x, y)}=\frac{d y^{\prime}}{\eta_{x}+\left(\eta_{y}-\xi_{x}\right) y^{\prime}-\xi_{y} y^{\prime 2}} \Longleftrightarrow \frac{d x}{1}=\frac{d y}{0}=\frac{d y^{\prime}}{0} .
$$

Dengan mengambil fraksi $\frac{d x}{1}$ dan $\frac{d y}{0}$ maka akan diperoleh

$$
\begin{array}{r}
\frac{d x}{1}=\frac{d y}{0} \\
\Longleftrightarrow d y=0 \\
\Longleftrightarrow y=c_{1}, c_{1} \in \mathbb{R}
\end{array}
$$

dan lebih lanjut tuliskan sebagai $u(x, y)=c_{1}=y$. Selanjutnya ambil fraksi $\frac{d x}{1}$ dan $\frac{d y^{\prime}}{0}$ maka akan diperoleh

$$
\begin{array}{r}
\frac{d x}{1}=\frac{d y^{\prime}}{0} \\
\Longleftrightarrow d y^{\prime}=0 \\
\Longleftrightarrow y^{\prime}=c_{2}, c_{2} \in \mathbb{R}
\end{array}
$$

dan tuliskan $v(x, y)=c_{2}=y^{\prime}$. Dengan menggunakan turunan total didapatkan persamaan berikut :

$$
\frac{d v}{d u}=\frac{y^{\prime \prime}}{y^{\prime}}=\frac{y^{\prime \prime}}{v} .
$$


Sehingga,

$$
\begin{aligned}
& \frac{d^{2} y}{d x^{2}}=-3 y \frac{d y}{d x}-y^{3} \\
\Longleftrightarrow & y^{\prime \prime}+3 u y^{\prime}+u^{3}=0 \\
\Longleftrightarrow & v \frac{d v}{d u}+3 u v+u^{3}=0 \\
\Longleftrightarrow & \frac{d v}{d u}=-\frac{3 u v+u^{3}}{v}
\end{aligned}
$$

Persamaan (17) merupakan persamaan diferensial orde satu yang merupakan hasil reduksi dari persamaan diferensial Painleve Ince.

Setelah diperoleh persamaan hasil reduksi (17), langkah selanjutnya adalah menyelesaikan persamaan tersebut. Dalam papernya, Gilmore [6] memberikan langkah-langkah penentuan solusi persamaan diferensial orde satu dengan menggunakan metode Simetri Lie. Dalam tulisan ini akan digunakan langkah-langkah tersebut untuk mencari solusi dari (17).

Langkah pertama yang dilakukan adalah mengetahui titik simetri dari (17). Perhatikanlah proposisi berikut :

Proposisi 3.1. Titik $\left(e^{\lambda} u, e^{2 \lambda} v\right)$ merupakan titik simetri dari (17).

Bukti : Untuk membuktikan bahwa $\left(e^{\lambda} u, e^{2 \lambda} v\right)$ merupakan titik simetri dari (17) cukup buktikan bahwa titik tersebut memenuhi kondisi simetri yaitu seperti pada (5). Misalkan $\hat{u}=e^{\lambda} u, \hat{v}=e^{2 \lambda} v$ dan $h(\hat{u}, \hat{v})=-\frac{3 \hat{u} \hat{v}+\hat{u}^{3}}{\hat{v}}$. Dengan menyesuaikan kondisi simetri persamaan (5), maka akan diperoleh :

$$
\frac{\hat{v}_{u}+h(u, v) \hat{v}_{v}}{\hat{u}_{u}+h(u, v) \hat{u}_{v}}=-\frac{3 \hat{u} \hat{v}+\hat{u}^{3}}{\hat{v}} .
$$

Substitusikan nilai $\hat{u}$ dan $\hat{v}$ ke ruas kanan dari (18), maka diperoleh persamaan berikut

$$
-\frac{3 \hat{u} \hat{v}+\hat{u}^{3}}{\hat{v}}=-\frac{3 e^{\lambda} u e^{2 \lambda} v+\left(e^{\lambda} u\right)^{3}}{e^{2 \lambda} v}=-\frac{3 u v e^{\lambda}+u^{3} e^{\lambda}}{v} .
$$

Disisi lain, substitusikan $\hat{u}$ dan $\hat{v}$ ke ruas kiri dari (18), maka diperoleh bentuk berikut

$$
\frac{\hat{v}_{u}+h(u, v) \hat{v}_{v}}{\hat{u}_{u}+h(u, v) \hat{u}_{v}}=\frac{0+h(u, v) e^{2 \lambda}}{e^{\lambda}+h(u, v) \cdot 0}=-\frac{3 u v e^{\lambda}+u^{3} e^{\lambda}}{v} .
$$

Karena persamaan (18) terpenuhi untuk $(\hat{u}, \hat{v})=\left(e^{\lambda} u, e^{2 \lambda} v\right)$ maka titik tersebut adalah titik simetri dari (17)

Setelah mengetahui titik simetrinya, langkah selanjutnya adalah menentukan vektor singgungnya, yaitu dengan menggunakan (6) dan (7) sehingga didapatkanlah

$$
\xi_{1}(u, v)=u, \eta_{1}(u, v)=2 v
$$

dan bentuk Lagrangenya adalah

$$
\frac{d u}{\xi_{1}(u, v)}=\frac{d v}{\eta_{1}(u, v)}=\frac{d v^{\prime}}{\eta_{1_{u}}+\left(\eta_{1_{v}}-\xi_{1_{u}}\right) v^{\prime}-\xi_{1_{v}} v^{\prime 2}} \Longleftrightarrow \frac{d u}{u}=\frac{d v}{2 v}=\frac{d v^{\prime}}{v^{\prime}} .
$$

Dari bentuk Lagrange tersebut akan diperolehlah koordinat kanoniknya, yaitu pertama ambil fraksi $\frac{d u}{u}$ untuk mendapatkan bentuk $s(u, v)$ sebagai berikut :

$$
s(u, v)=\int \frac{1}{u} d u=\ln u
$$


dan penentuan $r(x, y)$ didapatkan dengan mengambil 2 fraksi $\frac{d u}{u}$ dan $\frac{d v}{2 v}$ sebagai berikut:

$$
\begin{array}{r}
\frac{d u}{u}=\frac{d v}{2 v} \\
\Longleftrightarrow 2 \int \frac{d u}{u}=\int \frac{d v}{v} \\
\Longleftrightarrow \ln u^{2}=\ln v+c \\
\Longleftrightarrow v=c_{0} u^{2}, c_{0} \in \mathbb{R}
\end{array}
$$

Sehingga didapat $r(u, v)=c_{0}=u^{-2} v$. Selanjutnya, ambil 2 fraksi $\frac{d v^{\prime}}{v^{\prime}}$ dan $\frac{d v}{2 v}$ sebagai berikut:

$$
\begin{array}{r}
\frac{d v^{\prime}}{v^{\prime}}=\frac{d v}{2 v} \\
\Longleftrightarrow 2 \int \frac{1}{v^{\prime}} d v^{\prime}=\int \frac{1}{v} d v \\
\Longleftrightarrow 2 \ln v^{\prime}=\ln v+c_{1} \\
\Longleftrightarrow v^{\prime 2}=c_{2} v, c_{2} \in \mathbb{R}
\end{array}
$$

Sehingga didapatkan $t\left(u, v, v^{\prime}\right)=c_{2}=v^{\prime 2} v^{-1}$.

Selanjutnya tuliskan transformasi antar koordinatnya, yaitu

$$
\begin{array}{r}
s=\ln u \rightarrow u=e^{s} \\
r=u^{-2} v \rightarrow v=r u^{2}=r e^{2 s} \\
t=v^{\prime 2} v^{-1} \rightarrow v^{\prime 2}=t v=t r e^{2 s} \Longleftrightarrow v^{\prime}=t^{1 / 2} r^{1 / 2} e^{s}
\end{array}
$$

Kemudian substitusi $(20),(21)$ dan (22) ke persamaan permukaan $F\left(u, v, v^{\prime}\right)=v^{\prime}+\frac{3 u v+u^{3}}{v}=$ 0 , yaitu

$$
\begin{aligned}
t^{1 / 2} r^{1 / 2} e^{s}+\frac{3 e^{s} r e^{2 s}+e^{3 s}}{r e^{2 s}} & =0 \\
\Longleftrightarrow t^{1 / 2} r^{1 / 2} e^{s}+3 e^{s}+e^{s} r^{-1} & =0 \\
\Longleftrightarrow e^{s}\left[t^{1 / 2} r^{1 / 2}+3+r^{-1}\right] & =0
\end{aligned}
$$

Sehingga diperoleh bentuk persamaan permukaan yang baru (tidak bergantung pada $s$ ) sebagai berikut :

$$
F(r, t)=t^{1 / 2} r^{1 / 2}+3+r^{-1}=0
$$

Dengan manipulasi aljabar bentuk (23) maka diperoleh

$$
t(r)^{1 / 2}=\frac{-3-r^{-1}}{r^{1 / 2}} .
$$

Dari pembahasan di atas diperolehlah koordinat kanonik $(r(u, v), s(u, v))=\left(u^{-2} v, \ln u\right)$ dan fungsi $t(r)$. Selanjutnya dengan menggunakan (12) diperolehlah bentuk $\frac{d s}{d r}$ sebagai berikut:

$$
\frac{d s}{d r}=\frac{s_{u}+v^{\prime} s_{v}}{r_{u}+v^{\prime} r_{v}}=\frac{1 / u+0}{-2 u^{-3} v+v^{\prime} u^{-2}}=\frac{1}{-2 u^{-2} v+v^{\prime} u^{-1}} .
$$

Substitusikan $r(u, v)=u^{-2} v,(20)$ dan (22) ke (25) diperolehlah

$$
\frac{d s}{d r}=-\frac{r}{2 r^{2}+3 r+1}
$$


Lebih lanjut,

$$
\begin{array}{r}
\frac{d s}{d r}=-\frac{r}{2 r^{2}+3 r+1} \\
\Longleftrightarrow d s=-\frac{r d r}{2 r^{2}+3 r+1} \\
\Longleftrightarrow \int d s=\int-\frac{r d r}{2 r^{2}+3 r+1} \\
\Longleftrightarrow s+c_{4}=\int \frac{1}{2 r+1} d r-\int \frac{1}{r+1} d r \\
\Longleftrightarrow s=\ln \left(\frac{(2 r+1)^{1 / 2}}{r+1}\right)+c_{6}, c_{6} \in \mathbb{R}
\end{array}
$$

Substitusikan kembali bentuk $r(u, v)=u^{-2} v$ dan $s(u, v)=\ln u$ ke (26) sebagai berikut :

$$
\begin{array}{r}
\ln u=\ln \left(\frac{\left(2 u^{-2} v+1\right)^{1 / 2}}{u^{-2} v+1}\right)+c_{6} \\
\Longleftrightarrow u=c_{7} \frac{\left(2 u^{-2} v+1\right)^{1 / 2}}{u^{-2} v+1} \\
\Longleftrightarrow\left(u^{-1} v+u\right)^{2}=c_{8}\left(2 u^{-2} v+1\right), c_{8} \in \mathbb{R} \\
\Longleftrightarrow u^{-2} v^{2}-2 c_{8} u^{-2} v+2 v=c_{8}-u^{2} \\
\Longleftrightarrow v^{2}+\left(2 u^{2}-2 c_{8}\right) v=c_{8} u^{2}-u^{4} \\
\Longleftrightarrow\left(v-\left(c_{8}-u^{2}\right)\right)^{2}=c_{8}{ }^{2}-u^{2} c_{8} \\
\Longleftrightarrow v=c_{8} \pm \sqrt{c_{8}{ }^{2}-c_{8} u^{2}}-u^{2}
\end{array}
$$

Kemudian substitusikan $u(x, y)=y$ dan $v(x, y)=y^{\prime}$ ke (27) maka akan didapatkan

$$
\begin{array}{r}
y^{\prime}=c_{8} \pm \sqrt{c_{8}{ }^{2}-c_{8} y^{2}}-y^{2} \\
\Longleftrightarrow \frac{d y}{c_{8} \pm \sqrt{c_{8}^{2}-c_{8} y^{2}}-y^{2}}=d x \\
\Longleftrightarrow \int \frac{d y}{c_{8} \pm \sqrt{c_{8}^{2}-c_{8} y^{2}}-y^{2}}=\int d x \\
\Longleftrightarrow \frac{c_{8} \pm \sqrt{c_{8}\left(-y^{2}+c_{8}\right)}}{c_{8} y}=x+c_{9}, c_{9} \in \mathbb{R} \\
\Longleftrightarrow c_{8} \pm \sqrt{c_{8}\left(-y^{2}+c_{8}\right)}=c_{8} x y+c_{10} y, c_{8} c_{9}=c_{10} \in \mathbb{R} \\
\Longleftrightarrow \pm \sqrt{c_{8}\left(-y^{2}+c_{8}\right)}=-c_{8}+y\left(c_{8} x+c_{10}\right) \\
\Longleftrightarrow c_{8}\left(-y^{2}+c_{8}\right)=c_{8}{ }^{2}+y^{2}\left(c_{8} x+c_{10}\right)^{2}-2 c_{8} y\left(c_{8} x+c_{10}\right) \\
\Longleftrightarrow y^{2}\left(c_{8}+\left(c_{8} x+c_{10}\right)^{2}\right)=y\left(2 c_{8}{ }^{2} x+2 c_{8} c_{10}\right) \\
\Longleftrightarrow y=\frac{2 c_{8}{ }^{2} x+2 c_{8} c_{10}}{c_{8}+c_{8}{ }^{2} x^{2}+2 c_{8} c_{10} x+c_{10}{ }^{2}} \\
\Longleftrightarrow \begin{array}{c}
2 k_{1} x+2 k_{2} \\
k_{1} x^{2}+2 k_{2} x+k_{3}
\end{array}, k_{1}=c_{8}{ }^{2}, k_{2}=c_{8} c_{10}, k_{3}=c_{8}+c_{10}{ }^{2}
\end{array}
$$

Dengan demikian diperolehlah solusi dari (13), yaitu ;

$$
y=\frac{2 k_{1} x+2 k_{2}}{k_{1} x^{2}+2 k_{2} x+k_{3}}, k_{1}, k_{2}, k_{3} \in \mathbb{R}
$$


Malik dkk, JMI Vol 15 No 1 April 2019, pp. 45-52,doi:10.24198/jmi.v15.n1.21022.45-52

\section{Simpulan}

Berdasarkan pembahasan di atas, hasil yang dapat dijadikan kesimpulan dari tulisan ini adalah metode simetri dapat digunakan untuk mereduksi persamaan Painleve Ince menjadi persamaan diferensial orde satu dan dapat ditentukan koordinat kanoniknya sehingga dapat ditentukan solusi eksaknya.

\section{DAFtar Pustaka}

[1] Martinot, Z., 2014, Solutions to Ordinary Differential Equations Using Methods of Symmetry, Paper Zachary Department of Mathematics, University of Washington.

[2] Singh, M., 2015, On Reduction of Some Differential Equations using Symmetry Methods, Journal of Natural Sciences Research, Volume 5, Issue 3, 2015, Pages 44 - 47.

[3] Estevez, P.G., Herranz, F.J., de Lucas, J., Sardon,C., 2016, Lie symmetries for Lie systems : applications to systems of ODEs and PDEs, Applied Mathematics and Computation, January 2016, Pages 1 - 30.

[4] Herstein, I.N.,1999, Abstract Algebra, 3ed, John Wiley and Son.

[5] Steinhour, R.A, 2013, The Truth About Lie Symmetries: solving Differential Equations With Symmetry Methods. Senior Independent Study Theses, Department of Mathematics and Computer Science, The College of Wooster.

[6] Gilmore, R, 2006, Lie groups, Lie Algebras, and some of their applications. Dover Publications. 